INTERVENTIONAL CARDIOLOGY AND SURGERY

\title{
Late outcome of Senning and Mustard procedures for correction of transposition of the great arteries
}

\author{
L Dos, L Teruel, I J Ferreira, J Rodriguez-Larrea, L Miro, J Girona, D C Albert, A Gonçalves, \\ M Murtra, J Casaldaliga
}

Heart 2005;91:652-656. doi: 10.1136/hrt.2003.029769

See end of article for authors' affiliations

.

Correspondence to: Dr Jaume Casaldàliga, Department of Congenital Heart Disease in the Adult and Paediatric Cardiology, Hospital Materno-Infantil Vall d'Hebron, Passeig Vall d'Hebron, 119-129, 08035 Barcelona, Spain; jcasalda@vhebron.net

Accepted 2 July 2004
Objectives: To evaluate late mortality and morbidity after an atrial switch procedure for correction of transposition of the great arteries (TGA) and to assess predictive factors for adverse outcome.

Setting: Tertiary referral centre.

Design and patients: Retrospective follow up study of 137 patients surviving hospitalisation for TGA atrial switch procedure (Mustard or Senning) in a single institution and divided into two groups (simple and complex) depending on presurgical anatomy. Several surgical and follow up factors were evaluated during 16.7 (5.6) years' follow up.

Results: Late mortality was $5.1 \%$ (95\% confidence interval $1.37 \%$ to $8.84 \%$ ) with sudden death as the most common cause. No significant difference was found between Mustard and Senning procedures and between the complex and simple groups in terms of mortality. Independent predictive factors for late mortality were a history of supraventricular tachyarrhythmias and advanced New York Heart Association (NYHA) functional class during follow up. A very common finding was development of sinus node dysfunction $(47.6 \%)$, which had no influence on mortality. There was little need for reintervention (5.1\%) and relatively few cases of right ventricular systolic dysfunction (14.6\%). During follow up, most patients (96.2\%) were in NYHA functional class I-II.

Conclusions: Overall long term outcomes of patients with atrial repair of TGA in the present era are encouraging in terms of late mortality and quality of life. Nevertheless, better outcomes may be offered through improved diagnostic methods for right ventricular function and better management of supraventricular tachyarrhythmias.
S ince 1958, when Senning introduced his atrial switch procedure, the prognosis for children born with transposition of the great arteries (TGA) has changed dramatically. ${ }^{1}$ With this procedure the venous return is directed to the contralateral atrioventricular valve and ventricle by means of an atrial baffle made of the patient's septal tissue. Some years later, Mustard described an alternative technique in which the atrial septum is excised and a pericardial or synthetic baffle is used to direct the venous return. ${ }^{2}$ If TGA is left untreated, mortality at the end of the first year of life is as high as $90 \%{ }^{3}$; this atrial switch offered the possibility of reaching adulthood. In spite of initial good results and because of late complications ( specially atrial arrhythmias ${ }^{4}$ and right ventricular dysfunction ${ }^{5}$ ), the arterial switch procedure has largely replaced these techniques since the mid 1980s. Nevertheless, there is still great interest in late outcome of these patients because of the large number of survivors in follow up and because atrial redirection is still a useful technique in cases in which arterial switch is not feasible. In this study, we summarise the experience in our institution since 1973, when the first atrial repair procedure was done.

This study aimed at assessing the long term results of corrective surgery for TGA in a single large tertiary referral centre performing both atrial repair techniques (Mustard from February 1973 to October 1978 and Senning from December 1978 to May 1997). Special attention was paid to several surgical and follow up variables and their potential relation to late complications and mortality.

\section{METHODS}

This was a collaborative project between the general and paediatric cardiology departments coordinated by the Unit of
Adult Congenital Heart Disease. It was a retrospective study of all patients followed up in our institution who were discharged after undergoing an atrial repair procedure (Senning or Mustard) for diagnosed TGA from 1973 to 1997. Patients were divided into two groups depending on their presurgical anatomy. Anatomy was considered to be complex if there was associated significant ventricular septal defect requiring closure, significant left ventricular outflow tract obstruction also requiring correction (20-40 mm $\mathrm{Hg}$ ), or in case of palliative switch where the presence of important pulmonary vascular disease discouraged ventricular septal defect closure (two patients). Otherwise, patients were considered to have a simple anatomy. The simple group was divided into two subgroups (Mustard or Senning) according to the specific technique used in each case. The complex group was considered as a whole given the small number of patients of this cohort.

Of a total of 201 patients with diagnosed TGA in our institution during the studied period (171 in the simple group: Mustard 50 and Senning 121; and 30 in the complex group: Mustard 7 and Senning 23), 173 were discharged after undergoing an atrial switch procedure. The surgical mortality rate for the simple group was $11.1 \%$ (Mustard $20 \%$ and Senning $7.4 \%$ ) and for the complex group, 30\% (Mustard $57.1 \%$ and Senning $21.7 \%$ ). A total of 147 surgical survivors were followed up at our institution (the remaining 26 were followed up at other institutions and were not enrolled in the study) with annual or biannual controls that included anamnesis, physical examination, ECG, radiography, Holter monitoring, and echocardiography. Ten patients were lost to follow up, so that the final study group comprised 137 patients: 118 in the simple group (89 Senning and 29 


\begin{tabular}{|c|c|c|c|}
\hline & \multicolumn{3}{|c|}{ Surgical procedure } \\
\hline & Senning & Mustard & Combined $^{*}$ \\
\hline Number & $89(65 \%)$ & $29(21 \%)$ & 19 (14\%) \\
\hline Male sex & $68 \%$ & $41 \%$ & $47 \%$ \\
\hline Age (years) & 0.8 & 1.3 & 2.7 \\
\hline $95 \% \mathrm{Cl}$ & 0.04 to 5.97 & 0.15 to 5.1 & 0.3 to 12.3 \\
\hline Weight (g) & 6727 (1912) & 8010 (3598) & 9691 (6926) \\
\hline $\begin{array}{l}\text { Previous intervention } \\
\text { Rashkind }\end{array}$ & $98 \%$ & $93 \%$ & $63 \%$ \\
\hline Hanlon-Blalock & $3 \%$ & $10 \%$ & $0 \%$ \\
\hline Waldhausent & $3 \%$ & $0 \%$ & $0 \%$ \\
\hline \multicolumn{4}{|c|}{$\begin{array}{l}\text { Weight data are mean (SD). } \\
{ }^{*} \text { Combined procedures were atrial switch procedure plus other } \\
\text { corrections in patients with complex transposition of the great arteries; } \\
\text { tsubclavian flap repair of coarctation of the aorta. } \\
\mathrm{Cl} \text {, confidence interval. }\end{array}$} \\
\hline
\end{tabular}

Mustard) and 19 in the complex group. The mean age at the end of follow up was 17.5 years, $95 \%$ confidence interval (CI) 16.5 to 18.5 years, range $0.66-32$ years. The mean (SD) follow up time for the study population was 16.7 (5.6) years (4.1 months to 27.3 years after intervention).

Table 1 shows presurgical variables and table 2 shows the follow up parameters studied.

Right ventricular function was evaluated by echocardiography at each visit and considered to be depressed when the ejection fraction (determined by Simpson apical four chamber view or visual estimate by experienced observer in case of poor acoustic window) was $<45 \%$ in two consecutive assessments or confirmed by means of other examinations (usually radionuclide angiocardiography).

The cardiac rhythm was classified into three groups: normal, sinus node dysfunction (according to criteria ${ }^{6}$ shown in table 3), and atrioventricular block.

\section{Statistical analysis}

Baseline variables were compared by $\chi^{2}$ test or $t$ test when appropriate. Differences in time to death between groups were analysed by a two sided log rank test. The Kaplan-Meier method was used to estimate cumulative survivals and to construct life table plots. Variables that a priori were thought to have a potential impact on survival in these patients were included in a multivariate analysis of mortality data. Relative hazards and 95\% CIs were calculated as hazard ratios obtained from Cox proportional hazard ratios.

Table 2 Follow up variables

\begin{tabular}{lccc}
\hline & \multicolumn{3}{l}{ Surgical procedure } \\
\cline { 2 - 4 } & $\begin{array}{l}\text { Senning } \\
\text { (n=89) }\end{array}$ & $\begin{array}{l}\text { Mustard } \\
\text { (n= 29) }\end{array}$ & $\begin{array}{l}\text { Complex } \\
\text { (n= 19) }\end{array}$ \\
\hline RV dilatation & $98.9 \%$ & $96.6 \%$ & $100 \%$ \\
RV dysfunction & $11 \%$ & $24.1 \%$ & $15.8 \%$ \\
NYHA class I-II & $98.9 \%$ & $96.6 \%$ & $84.2 \%$ \\
Tachyarrhythmia & $10.1 \%$ & $20.7 \%$ & $15.8 \%$ \\
Bradycardia & $55.1 \%$ & $48.3 \%$ & $21.1 \%$ \\
Pacemaker implant & $9 \%$ & $10.3 \%$ & $0 \%$ \\
Baffle obstruction & $11.2 \%$ & $31 \%$ & $5.2 \%$ \\
Severe TR & $5.6 \%$ & $6.9 \%$ & $26.3 \%$ \\
Reintervention & $4.5 \%$ & $10.3 \%$ & $10.5 \%$ \\
Medical treatment & $10.1 \%$ & $17.2 \%$ & $42.1 \%$ \\
Pregnancy & $1.1 \%$ & $10.3 \%$ & $0 \%$ \\
Sequelae & $13.5 \%$ & $10.3 \%$ & $26.3 \%$ \\
\hline
\end{tabular}

NYHA, New York Heart Association; RV, right ventricular; TR, tricuspid regurgitation.
Table 3 Sinus node dysfunction diagnostic criteria ${ }^{6}$

1. Sinus bradycardia

- Neonates and infants: $<60$ beats/min asleep and $<80$ beats/min awake

- Children aged 2-6 years: $<60$ beats $/ \mathrm{min}$

- Children aged 7-11 years: $<45$ beats $/ \mathrm{min}$

- Adolescents and young adults: $<40$ beats $/ \mathrm{min}$

- Endurance and other highly trained athletes: $<30$ beats $/ \mathrm{min}$

2. Severe sinus arrhythmia (variation in RR interval of $\geqslant 100 \%$ )

3. Sinus pause or arrest

4. Escape rhythms at slow rate

5. Sinoatrial exit block (second degree, type I and II)

6. Bradycardia/tachyarrhythmia

\section{RESULTS}

Mortality

Among the 137 patients in the final cohort, seven died during follow up $(5.1 \%, 95 \%$ CI $1.37 \%$ to $8.84 \%)$, four in the simple group and three in the complex group at an average (SD) of 10.7 (10.7) years (median 12.4 years) after surgical repair (range 1.2 months to 21.5 years). The most common cause was sudden death $(42.8 \%)$. Postsurgical survival rate at 10 , 15 , and 20 years was $99 \%, 95 \%$, and $91 \%$, respectively, in the simple group (no significant differences between Mustard and Senning cohorts) and $89 \%, 82 \%$, and $82 \%$, respectively, in the complex group (fig 1).

None of the surgical variables studied had a significant influence on late mortality. The follow up variables related to mortality were severe tricuspid regurgitation $(p=0.015)$, advanced New York Heart Association (NYHA) functional class $(p<0.001)$, and tachyarrhythmias $(p=0.048)$. Two additional variables nearly reached significance in the univariate analysis ( simple $v$ complex, $\mathrm{p}=0.056$, and need for reoperation, $\mathrm{p}=0.068$ )

Multivariate analysis showed that only tachyarrhythmias and advanced NYHA functional class were independent predictors of mortality (table 4).

Table 5 summarises variables of every patient who died.

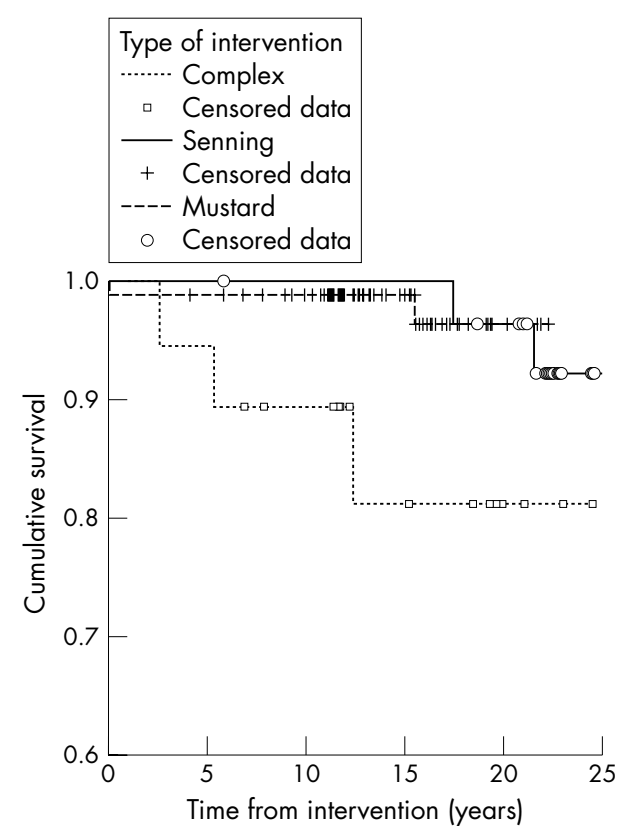

Figure 1 Cumulative survival (Kaplan-Meier). 


\begin{tabular}{|c|c|c|c|}
\hline Factor & $\mathrm{p}$ Value & $\begin{array}{l}\text { Hazard } \\
\text { ratio }\end{array}$ & $95 \% \mathrm{Cl}$ \\
\hline Severe TR & 0.16 & 3.9 & 0.5 to 28 \\
\hline NYHA class I-II & 0.033 & 6.16 & 1.15 to 32 \\
\hline Tachyarrhythmia & 0.049 & 5.59 & 1.006 to 31 \\
\hline Surgical procedure & 0.26 & 3.29 & 0.4 to 26 \\
\hline RV dysfunction & 0.6 & 0.55 & 0.06 to 5.05 \\
\hline
\end{tabular}

\section{Repeat operations}

After the initial procedure, seven additional operations were needed during follow up: two for baffle obstruction, one for baffle leak, one for superior vena cava obstruction, one interventricular septum defect closure (patient initially treated with a palliative switch), one tricuspid valve replacement for severe tricuspid regurgitation, and one mitral valve replacement for severe mitral regurgitation of iatrogenic surgical cause.

There were no surgical deaths during reinterventions. No significant differences were found between the simple and complex cohorts in terms of need for repeat operation.

\section{Rhythm disturbances}

Cardiac rhythm follow up was by ECG at every annual visit and by annual or biannual Holter recording. The most frequent disturbance registered was significant sinus rhythm dysfunction (according to diagnostic criteria shown in table 3 ) affecting $47.6 \%$ of the whole cohort at the end of follow up. The survival rate free of sinus node dysfunction at 5, 10, 15, and 20 years was of $82 \%, 82 \%, 63 \%$, and $46 \%$, respectively, in the Mustard cohort, 53\%, 44\%, 40\%, and 40\%, respectively, in the Senning cohort, and $94 \%, 70 \%, 70 \%$, and $70 \%$, respectively, in the complex group.

At the end of follow up, patients in the complex group presented significantly less sinus node dysfunction than patients in the simple group $(\mathrm{p}<0.05)$. In the simple group, the Senning cohort developed sinus node dysfunction sooner than the Mustard cohort (accumulated incidence during first five years, $57 \%$ v $7.6 \%$ ). Hanlon-Blalock septectomy preceding atrial switch was the only factor significantly related to development of sinus node dysfunction $(p<0.01)$.

Pacemaker implantation was mandatory in eight patients (12.5\% of total sinus node dysfunction), with symptomatic episodes in five (syncope or dizziness). There were also two cases of complete atrioventricular block and one of second degree atrioventricular block, all of them requiring pacemaker implantation. The average (SD) time of pacemaker implantation was 9.4 (5.2) years (range 1.3-17.7 years) after surgical repair.

The incidence of clinical tachyarrhythmias in the whole cohort was $13.1 \%$ ( 14 atrial flutter-fibrillation and four other supraventricular tachycardia) with an average (SD) time of appearance 8.7 (7.4) years (range 2.6 months to 21 years) after surgical repair.

\section{Echocardiographic data}

The great majority of patients had a dilated right ventricle $(98 \%)$ but only $14.6 \%$ (20 patients) developed systolic dysfunction (average (SD) time 14.3 (5.4) years after surgical repair). That condition led to an indication for cardiac transplantation in three patients that was carried out without problems in two of them. The third patient died suddenly while on the waiting list.

The presence of baffle obstruction was also followed up by echocardiographic examination, with $2.9 \%$ severe obstructions (three pulmonary venous pathway stenoses requiring surgical repair and one systemic venous pathway stenosis) and $11.6 \%$ mild to moderate obstructions ( 11 pulmonary and five systemic venous pathway stenoses). Of note, up to one third of patients undergoing the Mustard technique had a baffle obstruction.

We observed severe tricuspid regurgitation in 12 patients $(8.8 \%)$ requiring valve replacement in only one. The average (SD) time for development of severe tricuspid regurgitation was $12.0(6.2)$ years after surgical repair (range 1.7 months to 20.0 years, median 12.8 years) with no cases detected before surgery. Factors significantly related to development of tricuspid regurgitation in univariate analysis were right ventricular dysfunction $(\mathrm{p}=0.016)$ and a complex anatomy $(\mathrm{p}=0.013)$.

\section{Functional status and quality of life}

During follow up, 96.2\% maintained functional class I-II.

Among the female patients, $7.2 \%$ (four patients) gave birth to four healthy babies. In three cases, pregnancy and birth developed without problems but in the forth case, the patient died during the first 48 hours after labour due to cardiogenic shock secondary to refractory supraventricular tachyarrhythmia. This patient had no history of right ventricular dysfunction or tricuspid regurgitation but did have atrial flutter-fibrillation.

Sixteen per cent of patients were receiving medical treatment at the end of follow up $(8.8 \%$ digitalis, $4.4 \%$

Table 5 Late mortality

\begin{tabular}{|c|c|c|c|c|c|c|c|}
\hline & \multicolumn{7}{|c|}{ Patient number } \\
\hline & $1^{*}$ & 2 & 3 & 4 & 5 & 6 & $7^{*}$ \\
\hline Date of surgery & $02 / 1975$ & $12 / 1977$ & $02 / 1982$ & $03 / 1988$ & $12 / 1988$ & $07 / 1990$ & $06 / 1993$ \\
\hline Age at surgery (years) & 3.0 & 1.2 & 0.2 & 2.6 & 1.2 & 0.6 & 17.4 \\
\hline Age at death (years) & 24.6 & 18.6 & 15.7 & 15.0 & 3.7 & 0.7 & 22.7 \\
\hline Surgical procedure & Mustard & Mustard & Senning & Combined & Combined & Senning & Combined \\
\hline Cause of death & $\begin{array}{l}\text { Cardiogenic } \\
\text { shock }\end{array}$ & Sudden & Endocarditis & Sudden & Not cardiogenic & Sudden & Cardiogenic shock \\
\hline Tachyarrhythmia & Flutter-AF & SVT & No & No & No & No & Flutter-AF \\
\hline Bradycardia & SND & No & $2^{\circ} \mathrm{AV}$ block & No & No & No & No \\
\hline Pacemaker & No & No & Yes & No & No & No & No \\
\hline Severe TR & No & Yes & No & Yes & Yes & No & No \\
\hline Reintervention & No & Baffle leak & No & No & TR & No & No \\
\hline RV dysfunction & No & No & No & Yes & No & No & No \\
\hline Treatment & No & No & No & ACEI, diuretics & No & No & Amiodarone \\
\hline Sex & Female & Female & Female & Female & Male & Male & Male \\
\hline
\end{tabular}


diuretics, $6.6 \%$ angiotensin converting enzyme inhibitors, and $4.4 \%$ antiarrhythmic drugs).

Neurological manifestations (seven cases of hemiparesis and eight cases of epilepsy) were found in 15 patients $(10.9 \%)$. These manifestations were mostly assumed to be related to thromboembolic events during the polycythaemic phase before surgical repair, since four of the cases of hemiparesis developed before surgery and two in the immediate postoperative period (information is lacking in the remaining case). All the epilepsy episodes appeared after surgery, generally with computed tomography suggesting prior silent stroke. Five other thromboembolic events were registered in other locations (renal veins, iliofemoral area, pulmonary thromboembolism) and all of them (neurological manifestations and other thromboembolic events) are incorporated in table 2 as sequelae.

\section{DISCUSSION}

Nowadays, the surgical technique of choice for correction of TGA is Jatene's anatomical repair, leaving physiological repair only for cases in which the Jatene procedure is not feasible. Nevertheless, there is a large cohort of patients who underwent the Senning or Mustard procedure 20-40 years ago that need to be followed up to be aware of their natural history. Some studies have been published that summarise different centres' experience and at the same time try to search for factors that may influence late outcome.

Clear differences appear in terms of late mortality when several series are consulted, which reflects more a different year for the beginning of the technique in each centre (and so, greater development of cardiac surgery conditions) than a real difference between institutional practices (that is, 5.1\% in our centre with the first intervention in $1974 ; 22 \%$ reported by Sarkar et $a l^{7}$ in the Mustard cohort with the first intervention in 1965).

Sudden death is the most common cause of death in our series as it has been in previous ones, and the history of tachyarrhythmias was an independent predictive factor for mortality. ${ }^{7-9}$ Some authors have hypothesised a relation between supraventricular tachyarrhythmias and death based on a rapid ventricular response documented in Holter recordings (that is, atrial flutter $1: 1$ ). On the one hand, increasing attention is being paid to diastolic dysfunction because a rapid heart rate may exacerbate the limitation of ventricular filling that is intrinsic to the atrial repair circulation, compromising cardiac output. ${ }^{7}$ In fact, in our series two patients without a history of right ventricular systolic dysfunction rapidly developed cardiogenic shock during an episode of refractory supraventricular tachyarrhythmia (table 5). One of them was a patient with complex TGA (severe pulmonary and subpulmonary stenosis) who was operated on at our institution at age 17 after other approaches (Blalock-Taussig fistula) due to a very adverse anatomy. On the other hand, some papers have reported cases of supraventricular tachyarrhythmias with rapid ventricular response degeneration into ventricular fibrillation and therefore sudden death. ${ }^{10}$

The other independent predictive factor for mortality in our series is advanced NYHA functional class, which has yielded more information about our patients' prognosis than right ventricular systolic function evaluation. This may mean that functional class identifies not only patients with a poor prognosis for systolic dysfunction but also those with impaired diastolic function. So even though it is a subjective parameter, it may have value from a clinical point of view. Another explanation for the lack of significance of right ventricular systolic dysfunction in our series is that the echocardiographic parameter used for its assessment was two dimensional quantification, which today is considered a poor method. Magnetic resonance is nowadays the ideal method for measuring right ventricular systolic function but, in the past few years, various studies assessed the value of several echocardiographic parameters based on tissue Doppler imaging or three dimensional echocardiography, which may also offer the possibility of evaluating diastolic function and are less expensive and time consuming than magnetic resonance imaging. ${ }^{12-14}$ The use of a poor diagnostic method for determining right ventricular function may also explain a real difference in the incidence of right ventricular systolic dysfunction reported by previous series $(14.6 \%$ in ours, $28 \%$ by Kirjavainen et al, $0.3 \%$ by Sarkar et $a l^{8}$, and $1 \%$ by Wells et $a l^{15}$ ).

Previous studies have shown clear differences in terms of late mortality between simple and complex cohorts. ${ }^{8}$ In our series, although mortality differed greatly $(3.3 \%$ for simple and $15.7 \%$ for complex groups), these differences were not significant. This is probably due to the small number of patients with complex disease $(n=9)$ and the small total number of deaths.

In our series the most frequent arrhythmia was sinus node dysfunction, affecting $47.6 \%$ of the whole group at the end of follow up. As seen in previous studies, in our series patients who underwent the Mustard procedure had a longer mean survival in sinus rhythm than the Senning cohort ${ }^{9}$ and the only predictive factor for the development of sinus node dysfunction was septectomy (Hanlon-Blalock procedure) previous to atrial correction. ${ }^{16}$ Nevertheless, sinus node dysfunction has never been found to be a predictive factor for mortality.

Lastly, in terms of quality of life (although our study did not specifically assess this complex parameter) we may say that the majority of patients enjoy a nearly normal life. Almost all of them $(96 \%)$ are in NYHA functional class I-II (consistent with many previous studies ${ }^{7-9}{ }^{17}$ ) and four of the women gave birth to healthy babies. However, we cannot ignore the $10.9 \%$ incidence of neurological sequelae (hemiparesis and epilepsy) and an undetermined number of learning disabilities and delay in psychomotor development that were not evaluated in the present study but are summarised in others. ${ }^{8}$

It is noteworthy that this study has been possible thanks to a close relationship between members of General Cardiology and Paediatric Cardiology departments of our centre, under the necessary coordination of the Unit of Congenital Heart Disease in the Adult. Adult patients with congenital heart diseases operated on in infancy present with a new pathology necessitating the creation of specific working groups to increase knowledge lacking in this challenging field.

In conclusion, the overall long term outcomes of patients with atrial correction of TGA in the present era are encouraging in terms of late mortality and quality of life. Nevertheless, two challenging problems need to be solved. First is the development of right ventricular dysfunction (either systolic or diastolic) with the real need for improvement in diagnostic methods (magnetic resonance imaging is nowadays the ideal means of assessing right ventricular systolic function but it is an expensive and time consuming technique. Second is the development of supraventricular tachyarrhythmias, which have been found to be an independent predictive factor for mortality. The great development in the field of electrophysiology may lead to a solution in the near future.

\footnotetext{
Authors' affiliations

L Dos*, L Teruel, I J Ferreira, J Rodriguez-Larrea, Department of General Cardiology, Hospital Materno-Infantil Vall d'Hebron, Barcelona, Spain L Miro, A Gonçalves, M Murtra, Cardiac Surgery, Hospital MaternoInfantil Vall d'Hebron, Barcelona
} 
J Girona, D C Albert, Paediatric Cardiology, Hospital Materno-Infantil Vall d'Hebron, Barcelona

J Casaldaliga*, Adult Congenital Heart Disease Unit, Hospital MaternoInfantil Vall d'Hebron, Barcelona

*Also the Universitat Autonoma de Barcelona, Barcelona, Spain

\section{REFERENCES}

1 Senning A. Surgical correction of transposition of the great vessels. Surgery 1959;45:966-80.

2 Mustard WT. Successful two-stage correction of transposition of the great vessels. Surgery 1964;55:469-72.

3 Tynan M, Anderson RH. Congenital heart disease. In: Julian DG, Camm AJ, Fox KM, et al, eds. Diseases of the heart. Philadelphia: WB Saunders, 1996:681-755

4 Deanfield J, Camm J, Macartney F, et al. Arrhythmia and late mortality after Mustard and Senning operation for transposition of the great arteries: an eight-year prospective study. J Thorac Cardiovasc Surg 1988;96:569-76.

5 Wong KY, Venables AW, Kelly MJ, et al. Longitudinal studies of ventricular function after the Mustard operation of transposition of the great arteries: a long term follow up. Br Heart J 1988;60:316-22.

6 Kugler JD. Sinus node dysfunction. In: Gillette PC, Garson A, eds. Pediatric arrhythmias: electrophysiology and pacing. Philadelphia: WB Saunders, 1990:250-60

7 Sarkar D, Bull C, Yates R, et al. Comparison of long-term outcomes of atrial repair of simple transposition with implications for a late arterial switch strategy. Circulation 1999;100(suppl II):I1176-181.

8 Kirjavainen M, Happonen JM, Louhimo I. Late results of Senning operation. J Thorac Cardiovasc Surg 1999; 117:488-95.
9 Birnie D, Tometzki A, Curzio J, et al. Outcomes of transposition of the grea arteries in the era of atrial inflow correction. Heart 1998;80:170-3.

10 Silka M, Kron J, McAnulty J. Supraventricular tachyarrhythmias, congenital heart disease and sudden cardiac death. Pediatr Cardiol 1992;13:1 16-8.

11 Lubiszewska B, Gosiewska E, Hoffman P, et al. Myocardial perfusion and function of the systemic right ventricle in patients after atrial switch procedure for complete transposition: long-term follow-up. J Am Coll Cardiol 2000;36: 1365-70.

12 Lidegran M, Odhner L, Jacobsson LA, et al. Magnetic resonance imaging and echocardiography in assessment of ventricular function in atrially corrected transposition of great arteries. Scand Cardiovasc J 2000;34:384-9.

13 Ishii $M$, Eto $G$, Tei $C$, et al. Quantification of the global right ventricular function in children with normal heart and congenital heart disease: a right ventricular myocardial performance index. Pediatr Cardiol 2000;21:416-21.

14 Tulevski II, van der Wall EE, Groenink M, et al. Usefulness of magnetic resonance imaging dobutamine stress in asymptomatic and minimally symptomatic patients with decreased cardiac reserve from congenital heart disease (complete and corrected transposition of the great arteries and subpulmonic obstruction). Am J Cardiol 2002;89:1077-81.

15 Wells WJ, Blackstone E. Intermediate outcome after Mustard and Senning procedures: a study by the Congenital Heart Surgeons Society. Semin Thorac Cardiovasc Surg Pediatr Card Surg Annu 2000;3:186-97.

16 Gelatt M, Hamilton RM, McCrindle BW, et al. Arrhythmia and mortality after the Mustard procedure: a 30-year single-centre experience. J Am Coll Cardiol 1997;29:194-201.

17 Blanch P, Gómez-Hospital JA, Serrano M, et al. The follow-up of transposition of the great arteries corrected with the Senning procedure. Rev Esp Cardiol 1995;48:42-8.

18 Moreno F, Hiraldo ME, Cordero NS, et al. Transposición de las grandes arterias. Seguimiento de los pacientes operados mediante corrección auricular. Rev Esp Cardiol 1992;45:117-27.

\section{IMAGES IN CARDIOLOGY}

Magnetic resonance imaging of anomalous origin of the left coronary artery from the pulmonary artery (Bland-White-Garland syndrome)

A

37 year old woman without a history of any cardiac disease presented with an incidentally detected left precordial systolic murmur. There was an anterior wall hypokinesia on echocardiography but no signs of valvar or congenital heart disease. Exercise testing showed relevant anterior ST segment depression suggestive of exercise induced ischaemia. Cardiac magnetic resonance (MR) imaging demonstrated hypokinesia and an area of subendocardial late enhancement in the anteroseptal left ventricular myocardium indicating nontransmural myocardial infarction.

Contrast enhanced MR coronary angiography showed an anomalous origin of the left coronary artery from the pulmonary trunk (arrow), known as Bland-WhiteGarland syndrome. The right coronary is enlarged (arrowhead). Right coronary angiography confirmed the diagnosis with retrograde filling of the left coronary artery and connection to the pulmonary trunk.

O Bruder

G V Sabin

J Barkhausen

o.bruder@elisabeth-essen.de
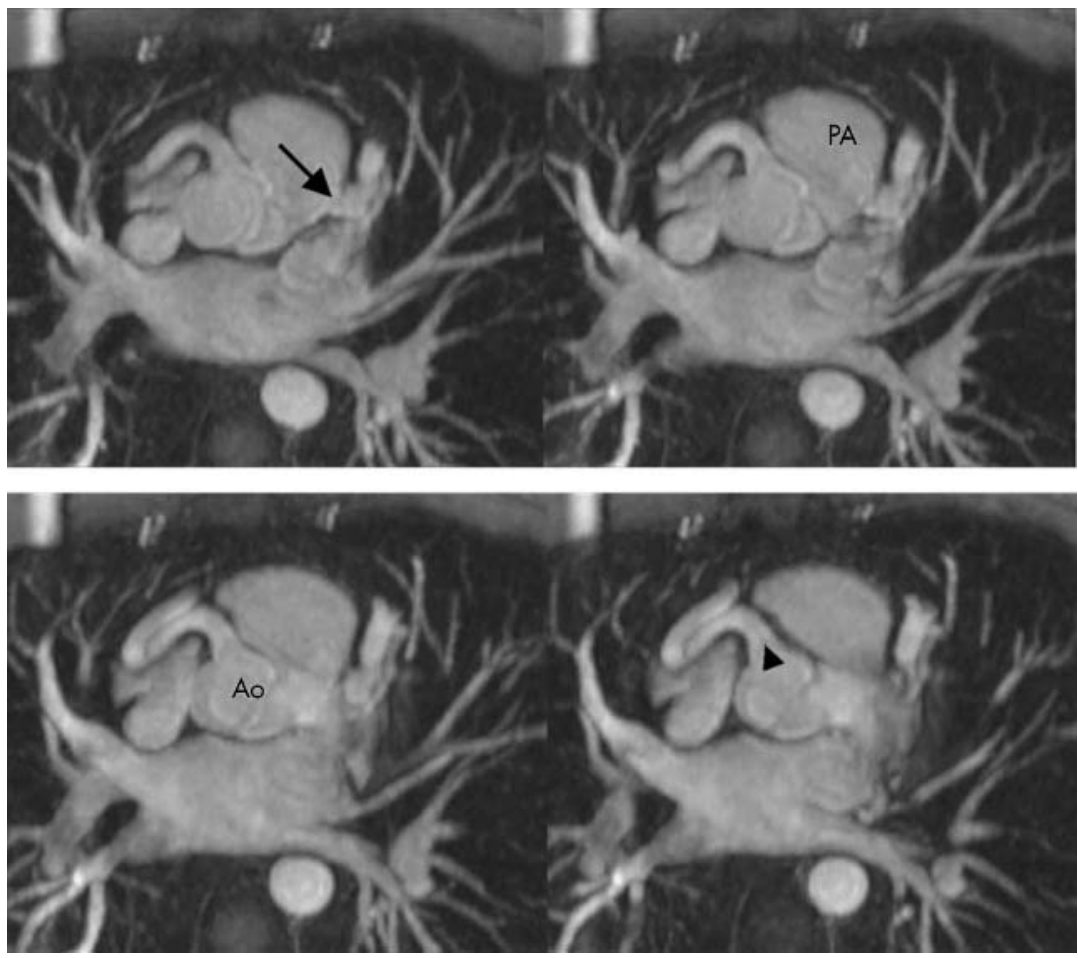